\title{
DIREITOS E CIDADANIA: REFLEXÕES SOBRE $O$ DIREITO À CIDADE
}

Thiago Aparecido Trindade

Cunhado pelo sociólogo e filósofo francês Henri Lefebvre em fins da década de 1960, o conceito de direito à cidade se difundiu na literatura internacional ao longo dos últimos anos e hoje não são poucos os autores que se lançam ao debate sobre o mesmo: Purcell (2003), Mitchell (2003), Rodrigues (2006), Fernandes (2007), Harvey (2008), Plyushteva (2009), Souza (2010), Marcuse (2010), para citar alguns. Fora da academia, no meio propriamente político e social, o V Fórum Urbano Mundial ${ }^{1}$, intitulado "O direito à cidade: unindo o urbano dividido", marcou a conquista de um alcance global por esse conceito. Este artigo tem dois objetivos principais: em primeiro lugar, debater o que significa o direito à cidade em termos legais, ou seja, ir além da dimensão política e filosófica subjacente ao termo; em segundo lugar, relacionar a noção de direito à cidade ao debate teórico sobre direitos e cidadania, sobretudo a partir das con-

\footnotetext{
${ }^{1}$ Promovido pela Organização Nações Unidas (ONU), o V Fórum Urbano Mundial realizou-se no Rio de Janeiro entre os dias 22 a 26 de março de 2001.
} 
tribuições de dois autores importantes nesse campo, a saber, Thomas H. Marshall e Norberto Bobbio.

Em relação ao primeiro objetivo, argumentaremos que a institucionalização jurídica do direito à cidade somente se justifica na perspectiva da função social da propriedade, ou seja, este é o princípio que define o direito à cidade em termos legais. Com relação ao segundo ponto, proporemos que esse direito deve ser interpretado enquanto um direito social e, por fim, explicitaremos quais são as principais implicações teóricas e analíticas dessa leitura. A estrutura deste artigo é simples. No primeiro tópico, partimos da definição seminal de Henri Lefebvre ([1968] 2008) acerca do direito à cidade para traçar as mediações analíticas necessárias e promover a discussão a que nos propomos, ou seja, o entendimento da dimensão jurídica desse direito. Para tanto, adotaremos a linha de raciocínio proposta pelo jurista e urbanista brasileiro Edésio Fernandes (2007), que 140 tem se destacado no debate acadêmico nacional e internacional referente ao direito à cidade. No segundo tópico, retomaremos alguns dos princípios teóricos essenciais do debate sobre os direitos e a constituição histórica da cidadania na sociedade contemporânea, procurando inserir o direito à cidade nessa problemática que é, ao mesmo tempo, teórica e política. Por fim, apresentaremos nossas considerações finais a respeito dos temas expostos e discutidos, na expectativa de darmos uma modesta contribuição ao debate contemporâneo sobre o direito à cidade.

\section{0 direito à cidade em uma perspectiva jurídica}

Em Lefebvre ([1968] 2008), o direito à cidade é uma utopia, uma plataforma política a ser construída e conquistada pelas lutas populares contra a lógica capitalista de produção da cidade, que mercantiliza o espaço urbano e o transforma em uma engrenagem a serviço do capital. Como sublinhado por Souza (2010, p. 318), para Lefebvre, o direito à cida- 
de não se refere ao direito a uma vida melhor e mais digna na cidade capitalista, mas sim a uma vida muito diferente, em uma sociedade, por sua vez, muito diferente, onde a lógica de produção do espaço urbano esteja subordinada ao valor de uso e não ao valor de troca. Assim, o direito à cidade, na proposição original desse autor, não se refere a mais um direito a ser institucionalizado no arcabouço jurídico do Estado. Desde o início, é preciso ter esse ponto em mente para não cobrar de Lefebvre algo que ele não se propôs a responder ou problematizar. A abordagem desse conceito exige, portanto, esta mediação analítica: se as preocupações de Lefebvre estavam voltadas para uma perspectiva de ruptura com a ordem urbana capitalista (e consequentemente com o próprio modelo de organização social inerente a esse modo de produção), as nossas são bem mais modestas, à medida que procuramos analisar o que significa o direito à cidade em termos institucionais e jurídicos na cidade e na sociedade capitalista. De qualquer modo, nossa análise se constrói a partir das contribuições originais desse autor, como será demonstrado nas linhas seguintes.

A discussão proposta por Henri Lefebvre nos remete à reforma urbanística promovida em Paris entre 1853 e 1870 pelo Barão Georges Haussmann, reforma esta que remodelou radicalmente o espaço urbano e expulsou para os subúrbios os trabalhadores, destituindo-os da urbanidade e da vida urbana, isto é, da possibilidade de vivenciar e experimentar a cidade. Esse remanejamento do tecido espacial parisiense foi uma resposta da classe dominante às jornadas operárias de junho de 1848. Lefebvre afirma que a segregação dos trabalhadores foi uma estratégia da burguesia de Paris para frear a democracia urbana nascente impulsionada pelas lutas populares, uma vez que, naquele momento, essa ordem política embrionária representava uma ameaça real aos interesses políticos das classes dominantes (Lefebvre, [1968] 2008, pp. 22-3). Se a cidade, como afirma o autor, 
constitui-se em um espaço de encontros potencialmente conflituosos ${ }^{2}$, o urbanismo segregacionista colocado em prática por Haussmann atuou contra a cidade, já que contribuiu para anular aquilo que é (ou deveria ser) peculiar e mais característico da vida urbana: os espaços de encontro e de convívio das diferentes classes e grupos sociais. No curso desse processo, os subúrbios, inicialmente criados para abrigar apenas a classe operária, passaram a exercer forte poder de atração sobre as camadas burguesas parisienses, esvaziando o centro da cidade em benefício dos escritórios e de um uso quase puramente comercial. O centro da cidade torna-se com isso um lugar de consumo ao mesmo tempo que representa o consumo do lugar (Lefebvre, [1968] 2008, p. 25). Graças ao remanejamento espacial, Paris se subordinou gradualmente à lógica e ao ritmo capitalista de produção do espaço. A especulação imobiliária desempenhou papel fundamental nesse cenário, ao atuar em favor da crescente 142 mercantilização do solo, e assim, em lugar das relações de valor de uso, relações de valor de troca passam a prevalecer. Ora, direito à cidade, para Lefebvre, refere-se, sobretudo, ao direito de experimentar e usufruir da centralidade urbana no ritmo do valor de uso em oposição ao valor de troca, o que exige necessariamente o rompimento com a lógica capitalista de produção do espaço; o direito à cidade, portanto, seria o direito

\section{[...] à vida urbana, à centralidade renovada, aos locais de encontro e de trocas, aos ritmos de vida e empregos do tempo que permitem o uso pleno e inteiro desses momentos e locais etc. [...]. A proclamação e a realização da vida urbana como reino do uso (da troca e do}

\footnotetext{
2 "A vida urbana pressupõe encontros, confrontos das diferenças, conhecimentos e reconhecimentos recíprocos (inclusive no confronto ideológico e político) dos modos de viver, dos 'padrões' que coexistem na Cidade" (Lefebvre, [1968] 2008, p. 22).
} 
encontro separados do valor de troca) exigem o domínio do econômico (do valor de troca, do mercado e da mercadoria) [...] (Lefebvre, [1968] 2008, p. 139).

Notemos, com isso, que as ideias de Lefebvre resultam de uma complexa elaboração teórica e filosófica. De nossa parte, compartilhamos a inquietação do jurista e urbanista brasileiro Edésio Fernandes (2007) em compreender o significado do direito à cidade em termos jurídico-institucionais na América Latina. Para esse autor, ao mesmo tempo que hoje se verifica uma crescente mobilização do conceito de Henri Lefebvre ${ }^{3}$, tem-se debatido muito pouco a respeito das implicações legais e jurídicas desse termo, o que, em parte, deve-se ao fato de que a definição do próprio Lefebvre não se volta para essas questões:

[...] o fato é que o conceito de "direito à cidade" de Henri Lefebvre foi muito mais uma plataforma político-filosófica e não explorava diretamente como, ou em que medida, a ordem legal determinava o padrão excludente de desenvolvimento urbano. Aos argumentos sociopolíticos de Lefebvre, deve ser acrescentada uma outra linha, ou seja, argumentos jurídicos que nos permitam construir uma crítica à ordem legal não apenas na perspectiva de valores sociopolíticos ou humanitários, mas desde dentro da própria ordem legal (Fernandes, 2007, p. 208).

A discussão proposta por Edésio Fernandes é plena de sentido, uma vez que o ordenamento legal desempenhou historicamente uma ação decisiva na produção e na

\footnotetext{
${ }^{3}$ Nesse aspecto, aliás, Souza alega que, a exemplo do termo sustentabilidade, o "direito à cidade" tornou-se atualmente uma espécie de "expressão guarda-chuva" (2010, pp. 315-6), utilizada para definir tudo ou quase tudo, o que tem contribuído para corromper e trivializar o conceito em questão à medida que o priva de qualquer rigor teórico e sentido analítico.
} 
reprodução das desigualdades sociais na América Latina, incluindo-se aí o padrão excludente e concentrador de riqueza da urbanização na região, cujos efeitos gerais são bem conhecidos: segregação socioespacial, exclusão territorial e degradação urbanístico-ambiental, punindo em especial as camadas empobrecidas da sociedade. Daí a importância de se construir uma crítica dessa ordem legal, já que uma ampla reformulação da mesma é condição sine qua non para a produção de cidades mais justas e menos desiguais do ponto de vista socioespacial. Fernandes ressalta que a obra de Henri Lefebvre em seu conjunto nos fornece elementos socioeconômicos, políticos, ideológicos e culturais essenciais para o entendimento acerca da urbanização, mas não se articula com a dimensão jurídico-institucional do problema (Fernandes, 2007, p. 208). Reafirmemos: não pretendemos construir uma crítica a Lefebvre, pois, como já destacamos anteriormente, não pode ser cobrado desse autor 144 algo que ele próprio não se propôs a refletir. A intenção é tão somente preencher uma importante lacuna teórica e contribuir com o debate atual sobre o direito à cidade em um aspecto que ainda recebe pouca atenção dos estudiosos, mas que ocupa uma dimensão crucial no combate a toda e qualquer forma de desigualdade.

Para tal finalidade, tomamos como referência a legislação brasileira atual, considerada uma das mais avançadas do mundo em matéria de política urbana (Fernandes e Alfonsin, 2009; Fernandes, 2007): a Lei n. 10.257/2001, conhecida como Estatuto da Cidade, que regulamenta os artigos 182 e 183 da Constituição Federal. Segundo Fernandes (2007, p. 204), essa lei representou um desenvolvimento importante da materialização do direito à cidade em termos legais, e não apenas enquanto uma noção política. Faz-se necessário pontuar que a aprovação do referido texto legal, que ocorreu no final do governo do ex-presidente Fernando Henrique Cardoso (entre 1995 e 2002), significou uma con- 
quista histórica de um conjunto de movimentos e organizações populares alinhados ao tema da reforma urbana no Brasil e foi fruto de um processo de mobilização social e política que teve início no princípio da década de 1960. O golpe militar de 1964 desarticulou os setores alinhados em torno dessa plataforma, fazendo com que o tema da reforma urbana "hibernasse" por cerca de duas décadas (Souza, 2004). Contudo, no final da década de 1970 e ao longo da década de 1980, graças, em parte, às intensas mobilizações sociais pela redemocratização do país, os sinais de enfraquecimento do regime militar tornam-se gradativamente mais visíveis. Durante a elaboração da Constituinte de 1988, os setores ligados ao ideário da reforma urbana rearticularam suas forças, criando o Movimento Nacional pela Reforma Urbana (MNRU), que reuniu movimentos populares de moradia, transporte, saneamento, associações e entidades profissionais (arquitetos, sanitaristas, assistentes sociais), entidades sindicais, acadêmicas e integrantes da igreja católica vinculados à teologia da libertação (Maricato, 2010).

O MNRU apresentou uma emenda constitucional de iniciativa popular, subscrita por cerca de 130 mil eleitores em todo o Brasil ${ }^{4}$, denominada Emenda Popular de Reforma Urbana. Em razão da resistência das forças políticas conservadoras, a proposta desse movimento não foi incorporada em sua totalidade, ficando na realidade muito aquém disso. Entretanto, pela primeira vez na história constitucional brasileira havia um capítulo específico sobre política urbana, localizado nos artigos 182 e 183, os quais continham o princípio da função social da cidade e da propriedade urbana. Ainda assim, naquele momento, parte significativa dos segmentos reformistas avaliou que seria necessário lutar pela regulamentação desses artigos consti-

\footnotetext{
${ }^{4} \mathrm{Na}$ época, foi estipulado que seriam necessárias 30 mil assinaturas de eleitores para a apresentação de uma Emenda Popular à Constituição (Maricato, 1994).
} 
tucionais com o intuito de avançar na construção de uma legislação mais específica para a política urbana - o que só aconteceria cerca de treze anos depois com a aprovação do Estatuto da Cidade, em 2001 ${ }^{5}$. A referida legislação tem como base o seguinte objetivo: "Para todos os efeitos, esta Lei, denominada Estatuto da Cidade, estabelece normas de ordem pública e interesse social que regulam o uso da propriedade urbana em prol do bem coletivo, da segurança e do bem-estar dos cidadãos, bem como do equilíbrio ambiental" (Brasil, 2001, grifos nossos).

O que significa regular o uso da propriedade urbana? Por que isso é necessário para garantir a segurança e o bem-estar coletivo dos cidadãos na cidade? Analisemos, em linhas gerais, algumas características da urbanização brasileira para responder a essas questões. Do ponto de vista histórico, as grandes cidades brasileiras e latino-americanas cresceram e se expandiram seguindo, sobretudo, a 146 lógica dos interesses privados, ao prevalecer uma política de laissez-faire no que toca à relação entre Estado e mercado (Quinto Júnior, 2003; Ribeiro, 2003; Fernandes, 2007). Muito embora o princípio da função social da propriedade, e a ideia de sua subordinação ao interesse coletivo, já constasse formalmente nas constituições brasileiras de 1934, 1946 e 1969 (Rodrigues, 1988), a concepção que prevaleceu no campo das interpretações jurídicas e da prática dos agentes privados sempre se pautou pela defesa da propriedade como um direito irrestrito e absoluto em face de qualquer outro. Segundo Fernandes, "a base jurídica dessa noção, ao longo do século XX, foi dada pelo Código Civil de 1916 aprovado quando apenas $10 \%$ de brasileiros viviam em cidades, no contexto de um país ainda fundamentalmente agrário, mas que vigorou até 2002”, e porque expressava o para-

\footnotetext{
${ }^{5}$ Para uma análise mais detalhada sobre o longo processo de negociação e embates políticos que conduziram à aprovação do Estatuto da Cidade, ver Grazia (2003), Silva (2002) e Bassul (2010).
} 
digma jurídico do liberalismo clássico, o Código Civil defendia "o direito de propriedade individual de maneira quase que absoluta" (2010, p. 61), o que contribuiu para limitar de maneira drástica a ação do poder público ao longo do desenvolvimento urbano brasileiro. Esse liberalismo exacerbado em relação à propriedade privada estimulou em grande medida a prática da especulação imobiliária, que consiste basicamente na retenção de terra e imóveis em razão da expectativa de sua valorização futura (Campos Filho, 1989; Villaça, 1998). Essa prática subordinou o solo urbano a um ritmo de expansão, na aparência, caótico, mas que, na verdade, atendia a uma lógica muito particular: a do mercado privado de terras. Como explica Maricato (1996; 2010), as áreas mais urbanizadas e melhor localizadas em relação ao centro da cidade sempre foram reservadas para as camadas médias e altas, aqueles segmentos cujo poder de inserção no mercado de consumo é alto o suficiente para a aquisição da terra urbanizada. Nesse cenário marcado pela não intervenção do Estado no mercado de terras, as grandes propriedades não desempenhavam efetivamente nenhuma função social, mas sim econômica, ou seja, o enriquecimento de seus detentores. Do outro lado do espectro social, em vista de seus baixos rendimentos econômicos, as camadas mais empobrecidas da população foram privadas ao longo da história da possibilidade de participar do mercado formal de habitação, ocupando, muitas vezes de forma ilegal, as áreas mais precárias do ponto de vista da infraestrutura urbana e mais distantes em relação às melhores localizações da cidade (Maricato, 1996, 2000, 2010; Kowarick, 1980, 2009; Rodrigues, 1988; Fernandes, 2007).

Dessa forma, sobretudo em razão da especulação imobiliária, produziu-se uma situação aparentemente paradoxal: enquanto um enorme contingente populacional se aglomerava na periferia da cidade vivendo em condições precárias ao extremo, inúmeros terrenos e imóveis vazios 
e/ou ociosos conformavam a paisagem urbana - um grande número deles, inclusive, na área central. Com isso, permanecem vários espaços vazios nessa área - os chamados vazios urbanos - ao passo que a malha da cidade se espraia de forma contínua e horizontal. O caso de São Paulo é emblemático, mas toda e qualquer grande cidade latino-americana serve como referência: Milton Santos aponta que, entre as décadas de 1950 e de 1970, a área urbana da Cidade do México cresceu mais de quatro vezes, sendo que a densidade populacional caiu de 16 para 11,7 habitantes $/ \mathrm{km}^{2}$ no mesmo período (1990, p. 19), o que significa que o crescimento da área urbana não é determinado pelas necessidades de acomodar a população no espaço, mas sim pelos interesses da especulação imobiliária. Com relação à São Paulo, dados preliminares do censo do Instituto Brasileiro de Geografia e Estatística (IBGE) para o ano de 2010 acusaram a existência de 290 mil imóveis 148 vazios na cidade, mais do que suficiente para abrigar toda a população paulistana que atualmente vive em áreas de risco (cerca de 130 mil famílias) (Estadão, 2010). Este é o resultado histórico de uma política urbana que conferiu enorme liberdade ao mercado em detrimento de um controle rigoroso do uso do solo e da propriedade por parte do Estado. O preço a ser pago por essa "opção" inclui também uma intensa degradação ambiental, uma vez que grande parte das moradias informais da população pobre é edificada em beiras de córregos, margens de mananciais de abastecimento público e encostas de morros, contribuindo para a ocorrência de desastres que ceifam centenas ou até milhares de vidas periodicamente (Maricato, 2011).

Configura-se, dessa forma, a situação que é descrita por Maricato nos seguintes termos: as classes populares têm direito à ocupação (ou à moradia), mas não direito à cidade, isto é, os segmentos mais pobres podem ocupar áreas na cidade, mas apenas determinadas áreas (1996, p. 63). A 
conivência do poder público para com a ocupação ilegal da terra urbana pelas camadas populares deve ser compreendida inclusive como uma estratégia de amortecimento das tensões sociais (Kowarick, 1980; Rodrigues, 1988; Maricato, 1996), mas há uma condição implícita para que essa tolerância ocorra de fato: as terras ocupadas precisam estar fora dos planos do mercado privado de habitação (Maricato, 1996; 2010). Dessa maneira, ao longo da história, as camadas mais empobrecidas foram impossibilitadas de usufruir da cidade de forma plena, isto é, foram privadas do acesso às melhores localizações do tecido urbano. Nessa perspectiva, ter direito à cidade significa poder usufruir das vantagens, dos serviços e oportunidades oferecidas pelas boas localidades do sistema urbano. $\mathrm{O}$ direito à cidade, portanto, não é equivalente ao direito à moradia; o primeiro é muito mais amplo e complexo, pois considera a localização do indivíduo no sistema urbano em seu conjunto e a possibilidade de acesso às melhores localizações da cidade. Não por acaso, o direito à cidade é muitas vezes associado pela literatura acadêmica (e pelos próprios ativistas sociais) ao direito de morar nas áreas centrais, visto que os centros históricos das grandes cidades possuem uma ampla gama de equipamentos coletivos e infraestrutura urbana, em comparação às áreas periféricas.

Mas é impossível garantir o direito à cidade para as camadas mais vulneráveis do ponto de vista socioeconômico sem a adoção, por parte do Estado, de uma política urbana rigorosamente pautada pela defesa dos interesses coletivos em detrimento dos interesses individuais de propriedade. Do ponto de vista jurídico, isso requer a incorporação do princípio da função social da propriedade, justamente com o intuito de regular o uso da propriedade e do solo urbano, coibindo assim a prática da especulação imobiliária. Nesse sentido, o Estatuto da Cidade impõe restrições ao direito individual de propriedade para garantir 
um mínimo de segurança e bem-estar aos cidadãos excluídos do mercado formal de habitação, ou seja, daquelas pessoas que não conseguem pagar por uma boa localização. Por isso, entendemos que o direito à cidade somente se justifica do ponto de vista jurídico na perspectiva da função social da propriedade urbana. Esta seria a "razão de ser" desse direito, ou, em outros termos, o que justifica e legitima sua existência legal.

Tal princípio, que, vale lembrar, já estava contido no capítulo sobre política urbana da Constituição Federal, está claramente expresso no artigo $2^{\circ}$ do Estatuto, onde se lê: "A política urbana tem por objetivo ordenar o pleno desenvolvimento das funções sociais da cidade e da propriedade urbana [...]". Isso significa que, na prática, o Estado deve valer-se de dispositivos jurídico-institucionais para regular o uso e ocupação do solo. Dentre os instrumentos disponibilizados pelo Estatuto da Cidade para tal finalidade, os 150 mais relevantes são os seguintes: a) parcelamento e edificação compulsórios; b) Imposto Predial e Territorial Urbano (IPTU) progressivo no tempo; c) desapropriação do imóvel (com pagamento em títulos da dívida pública) ${ }^{6}$. De acordo com Barros et al. (2010, p. 97), tais dispositivos jurídicos e tributários têm a função primordial de evitar a formação dos vazios urbanos, coibir a especulação imobiliária e ampliar o acesso da população mais pobre às áreas urbanizadas, "concretizando o preceito constitucional da função social da propriedade".

De todo modo, deve ser lembrado também que o Estatuto da Cidade não se baseia unicamente no princípio da função social da propriedade, o que significa dizer que, em termos jurídicos, o direito à cidade não se traduz apenas por meio de tal norma. Na proposta legal do Estatuto, mais especificamente conforme o artigo $43^{\circ}$, que trata da gestão demo-

\footnotetext{
${ }^{6}$ Para uma discussão mais detalhada sobre esses mecanismos, ver Cardoso (2003).
} 
crática da cidade, há uma ênfase muito forte na participação da sociedade organizada na formulação e estabelecimento da política urbana em nível municipal - que é a instância responsável pela elaboração dessa política no Brasil -, que pode se dar por meio de audiências e consultas públicas, conselhos gestores, conferências sobre temas urbanos nos três níveis de governo etc. É importante salientar que a referida legislação torna a participação popular obrigatória, ou seja, não é uma questão de vontade política das administrações municipais, como acontece com o orçamento participativo, por exemplo. Segundo o artigo $52^{\circ}$ do Estatuto, o prefeito municipal incorre em improbidade administrativa caso não permita a participação dos grupos civis organizados na elaboração do Plano Diretor do município, o instrumento básico da política de desenvolvimento e expansão urbana. E a participação da sociedade na elaboração da política urbana municipal não é algo trivial ou secundário. Pelo contrário, para os movimentos sociais, ela é uma reivindicação tão importante quanto o estabelecimento do princípio da função social da propriedade. Como salientam Barros et al. (2010, p. 115), na tentativa de "superar a enorme desigualdade social que caracteriza as cidades brasileiras", o Estatuto propõe um processo participativo capaz de possibilitar que a população de baixa renda, "sempre excluída do planejamento das cidades, passe a participar das decisões sobre a regulação do uso e ocupação do território e a destinação dos investimentos públicos”. Isso significa dizer que o direito à cidade inclui o direito à participação da sociedade organizada na gestão e na administração municipal, ou seja, é inviável avançar na construção de um modelo mais justo e democrático de cidade sem democratizar o aparelho burocrático estatal que toma as decisões referentes aos investimentos e à alocação de recursos no território urbano.

Entretanto, o direito à participação, por si só, é incapaz de definir o direito à cidade no plano do ordenamento jurí- 
dico-legal. Isso porque o direito à participação da sociedade na formulação das políticas públicas é algo mais genérico, uma vez que ele é garantido em praticamente todas as áreas de políticas setoriais, isto é, na saúde, no meio ambiente, na assistência social, na cultura etc. $\mathrm{O}$ direito de participar da política urbana, portanto, não confere nenhuma particularidade ao direito à cidade diante dos outros direitos. Reafirmamos, por isso, que, em termos jurídicos, o direito à cidade somente se justifica na perspectiva da função social da propriedade urbana, princípio que lhe garante uma função e um lugar específico no ordenamento legal do arcabouço jurídico do Estado. Isso não significa, de modo algum, minimizar a importância da participação para a conquista do direito à cidade pelas camadas urbanas desfavorecidas, mas sim reconhecer que a participação é um meio para se alcançar determinados fins, e não um fim em si mesmo. A partir de nossa interpretação do significado jurídico do direito à 152 cidade, cabe formular a seguinte questão: como situar esse direito no debate teórico clássico sobre o tema dos direitos e da cidadania?

\section{0 direito à cidade no debate teórico sobre direitos e cidadania}

Segundo Norberto Bobbio (1992), os direitos são historicamente determinados, isto é, variam conforme as circunstâncias conformadas no e pelo processo histórico, e, em especial, de acordo com o alcance e a dimensão das lutas sociais. Por isso, direitos que foram considerados fundamentais e invioláveis em determinado momento histórico podem ser submetidos a severas restrições em outras épocas - como aconteceu com o direito à propriedade privada. A contribuição do sociólogo inglês Thomas H. Marshall ([1949] 1967) é de importância capital para a compreensão das transformações históricas que paulatinamente ampliaram o leque de direitos na sociedade ocidental nos últimos dois séculos, o que alte- 
rou de forma substancial a concepção de cidadania vigente no mundo contemporâneo. A despeito das inúmeras críticas que Marshall recebe, especialmente em razão de uma concepção linear-evolutiva do desenvolvimento da cidadania na história, a discussão proposta pelo autor no clássico texto Cidadania e classe social expõe elementos de importância incontestável para o debate sobre a constituição da cidadania no presente momento histórico (Souki, 2006). Não por acaso, como recorda Saes (2003), mesmo cinco décadas após a publicação original de sua obra, Marshall continua a ser uma referência teórica essencial para todos aqueles que se lançam ao estudo da cidadania na sociedade atual. Ou seja, como todo esquema teórico, a proposta de Marshall apresenta problemas, mas também virtudes.

De acordo com a análise marshalliana, a cidadania se refere a um status que permite ao indivíduo a participação integral na comunidade política e na herança social, processo cuja efetivação depende em larga medida da construção de um sentimento de pertencimento capaz de conectar os indivíduos à comunidade mais ampla, esta circunscrita nos limites do Estado-nação. A partir dessa perspectiva, Marshall divide a cidadania em três elementos, a saber, o civil, o político e o social ([1949] 1967, pp. 62-3). O elemento civil se refere às liberdades básicas e fundamentais dos indivíduos: liberdade de ir e vir, liberdade religiosa e de pensamento, direito de propriedade, de celebração de contratos válidos perante a justiça e o direito à própria justiça. Este último, como lembra Marshall, difere dos outros direitos contidos no elemento civil, já que ele diz respeito à possibilidade de se acessar o sistema judiciário com o objetivo de defender todos os outros direitos em pé de igualdade com relação aos demais membros da comunidade. O elemento político concerne ao direito de participar diretamente do exercício do poder político, ou, em outros termos, ao direito de votar e de ser votado. O elemento social, por fim, traduz-se no 
direito a um mínimo de bem-estar e segurança socioeconômica, bem como à possibilidade de participar por inteiro da herança constituída socialmente. Deve-se ressaltar ainda que a cada um dos três elementos da cidadania corresponde um quadro institucional específico: os tribunais de justiça são as instituições associadas de modo direto aos direitos civis; o parlamento e as outras instituições que representam de modo direto a população correspondem aos direitos políticos e o sistema educacional e a rede de serviços sociais se referem aos direitos sociais (Marshall, [1949] 1967, pp. 63-4).

De acordo com Josué Pereira da Silva, o elemento social é, na realidade, "o traço distintivo do modelo de cidadania de Marshall”. Sobretudo na noção de cidadania social "Marshall encontra o ponto de apoio para uma lógica promotora de igualdade capaz de se contrapor à lógica da economia de mercado que favorece a produção da desi154 gualdade" (2010, p. 116). Com efeito, a natureza de cada um desses elementos constituintes da cidadania apontados por Marshall os diferencia dos demais e lhes confere características particulares. Interessa-nos enfatizar neste artigo as diferenças existentes entre os elementos civil e social. Nessa direção, é importante resgatar uma distinção feita por Bobbio (1992): os direitos e as liberdades civis, também chamados de "direitos individuais tradicionais", consistem essencialmente em obrigações negativas, uma vez que exigem a não interferência do poder estatal para sua realização efetiva (no esquema marshalliano, a exceção seria o direito à justiça, que obriga o Estado a possibilitar o acesso das camadas mais pobres da população ao aparelho judiciário de forma gratuita ou menos custosa possível); por sua vez, os direitos sociais consistem em obrigações positivas, pois só podem se concretizar a partir da intervenção direta do aparelho estatal na economia e na sociedade, ao inevitavelmente restringir certas liberdades individuais. Bobbio 
afirma então que os direitos individuais podem ser entendidos de fato enquanto liberdades, ao passo em que os direitos sociais devem ser classificados como poderes: "Quanto mais aumentam os poderes dos indivíduos, tanto mais diminuem as liberdades dos mesmos indivíduos" (1992, p. 21). A partir de tais proposições, pode-se dizer que a luta pela cidadania na sociedade moderna se configura basicamente a partir do conflito entre liberdades e poderes, ou, em outros termos, entre as liberdades individuais tradicionais e a luta pela criação de mecanismos jurídico-institucionais garantidores de uma proteção mínima aos cidadãos em face da dinâmica excludente e concentradora de riqueza do mercado capitalista. Não por acaso, Marshall ([1949] 1967, p. 76) afirmou que, no século XX, a cidadania e o capitalismo estavam em guerra (e com certeza continuam ainda hoje), visto que a primeira se baseia no princípio da igualdade enquanto que o segundo se funda no da desigualdade, cidadania e capitalismo conformam, portanto, polos antagônicos. Em raciocínio similar, Bobbio argumenta que as sociedades "são mais livres na medida em que menos justas e mais justas na medida em que menos livres" (1992, p. 43), ou seja, quanto menor for a intervenção do Estado na vida econômica e social, maior a tendência de se produzir uma sociedade desigual e injusta; por isso, liberdades e poderes não são complementares, mas sim incompatíveis: "Os direitos sociais, em sua forma moderna, implicam [...] na subordinação do preço de mercado à justiça social, na subordinação da barganha livre por uma declaração de direitos”, impactando e modificando diretamente a estrutura de classe inerente ao sistema capitalista (Marshall, [1949] 1967, p. 103).

A partir desse debate teórico e de forma coerente com a discussão apresentada no tópico anterior, consideramos que o direito à cidade deve ser interpretado enquanto uma obrigação positiva do Estado, o que o torna, portanto, um direito social, cuja finalidade reside na garantia da segurança mate- 
rial e do bem-estar coletivo aos cidadãos diante dos mecanismos excludentes que constituem o fundamento da economia de mercado. No caso da cidade, tais mecanismos se manifestam na maneira como o espaço urbano é produzido e apropriado pelos interesses capitalistas, sobretudo a partir da especulação imobiliária, que segrega a população trabalhadora de baixa renda das melhores localizações do sistema urbano. $\mathrm{O}$ estabelecimento e garantia do direito à cidade a esses segmentos sociais excluídos do circuito mercantil exige, portanto, uma ação positiva do Estado, que necessariamente implica em restrições do direito individual dos grandes proprietários de terras e imóveis, ao estabelecer normas públicas de controle e regulação da propriedade urbana. Dessa forma, nos termos do debate teórico aqui exposto, a luta pela instauração do direito à cidade reproduz o conflito entre direitos sociais (obrigações positivas), de um lado, e direitos civis (obrigações negativas), do outro.

156 Para uma compreensão mais adequada dessa dinâmica tensa e conflituosa, uma pista analítica importante pode ser encontrada na obra do próprio Marshall. Segundo o autor, os direitos civis são indispensáveis para a emergência e a manutenção da economia de mercado, à medida que conferem "a cada homem [...] o poder de participar, como uma unidade independente, na concorrência econômica”, seja como vendedores ou como compradores da força de trabalho, relação que constitui a base sobre a qual se edifica o sistema capitalista (Marshall, [1949] 1967, p. 79). Contudo, a recíproca não é verdadeira: os direitos sociais não são indispensáveis ao funcionamento da economia de mercado. É evidente que a incorporação de tais direitos contribui para a estabilização política e social de qualquer sistema capitalista, visto que, caso as demandas populares pelos direitos sociais não sejam atendidas, o risco de uma convulsão social generalizada se tornaria cada vez maior. Mas, a rigor, a economia de mercado não depende dos direitos 
sociais para existir, e a instauração efetiva destes implica inevitavelmente em certas restrições aos direitos civis. Por essa razão, para muitos pensadores e intérpretes do direito, os direitos sociais não possuem status jurídico de direitos fundamentais; estes seriam apenas aqueles relativos às liberdades negativas, ou seja, aos direitos individuais tradicionais. Carlos Miguel Herrera (2003, p. 75) aponta que, se por um lado, podemos encontrar enunciados normativos acerca dos direitos sociais na maioria das constituições ocidentais contemporâneas, por outro, deve ser lembrado que a doutrina dominante na maioria dessas sociedades sustenta que estes não seriam direitos autênticos, exigíveis em face dos tribunais e do sistema judiciário em seu conjunto; antes, os direitos sociais se constituiriam em objetivos, fins e princípios gerais. $\mathrm{O}$ argumento dessa doutrina é, naturalmente, de cunho liberal: como os direitos sociais exigem uma ação positiva do Estado, isso inibiria e restringiria o exercício das liberdades fundamentais, isto é, o Estado estaria, na verdade, cometendo um atentado contra as liberdades básicas e essenciais dos indivíduos.

Isso significa dizer que a instauração dos direitos sociais é um processo particularmente complexo. Entre o reconhecimento jurídico desses direitos e sua aplicação efetiva no mundo real, há um longo caminho a ser trilhado pelos grupos e classes sociais diretamente interessados em sua implementação. No seio dessa problemática, Danilo Zolo (2005) nos oferece uma relevante contribuição. Numa tentativa de fazer uma apreensão crítica da proposta teórica de Marshall e inverter o seu "otimismo evolutivo" no que toca à constituição histórica da cidadania, Zolo defende a tese da "lei da eficácia decrescente dos direitos": à medida que passamos do campo dos direitos civis aos direitos políticos e, por fim, aos direitos sociais, a garantia concreta dos direitos torna-se de maneira gradual mais seletiva e juridicamente imperfeita (2005, pp. 96-7). Para esse autor, cada um dos 
elementos constitutivos da cidadania (civil, político e social) estabelece uma relação específica com as instâncias gerais de um sistema político e cultural equivalente a uma economia de mercado, onde o ideário liberal de sociedade predomina em larga medida. Nesse sentido, a despeito do reconhecimento e da titularidade formal dos direitos, haveria uma eficácia decrescente em seu desfrute por parte dos cidadãos. Dessa forma, enquanto os direitos civis pertencem à normalidade fisiológica dos ordenamentos liberal-democráticos, o que faz com que sua garantia seja praticamente automática e desde sempre legitimada, "somente uma permanente 'luta pelo direito' pode dar eficácia aos direitos políticos e, mais ainda, aos direitos sociais" (Zolo, 2005, p. 97). Ou seja, a garantia dos direitos políticos e sociais, mas em especial destes últimos, depende essencialmente da mobilização e da luta social, uma vez que a materialização concreta desses direitos afronta de forma significativa os interesses das 158 classes detentoras do poder econômico. Como pontuado por Saes (2003, p. 22), o reconhecimento e instauração dos direitos sociais resultam "da eventual capacidade das lutas populares de impor às classes dominantes um compromisso sobre novos direitos; direitos esses que, por si mesmos, não destroem o capitalismo, mas que nem por isso são desejados pelas classes dominantes".

Ora, este é exatamente o quadro da luta pela efetivação do Estatuto da Cidade na sociedade brasileira nos dias de hoje. Como sublinhado por Rodrigues (2006), a referida legislação não atua contra a lógica capitalista de acumulação; pelo contrário, ela reconhece a propriedade privada da terra, mas impõe limites à utilização desta. Isto é, a efetivação do Estatuto da Cidade e, portanto, do direito à cidade, não implicaria de modo algum em uma ruptura com a lógica capitalista e mercantil de produção da cidade, mas por certo restringiria de forma significativa as possibilidades de ganhos e apropriação da renda fundiária urbana pelos 
agentes ligados ao mercado imobiliário, o que naturalmente suscita reações negativas destes a toda e qualquer tentativa de efetivação da referida lei, sobretudo no que tange aos instrumentos jurídico-urbanísticos de coibição da especulação imobiliária (Ribeiro, 2003; Quinto Júnior, 2003). A cidade de São Paulo constitui-se atualmente em um dos principais palcos da luta pelo direito à cidade no Brasil. $\mathrm{O}$ movimento de moradia atuante no centro da capital paulista, congregado especialmente em torno de duas organizações, a saber, a União dos Movimentos de Moradia (UMM) e a Frente de Luta por Moradia (FLM), conseguiu inserir na opinião pública o debate sobre o direito à moradia das classes populares nas áreas centrais, o que remete às discussões sobre a função social da propriedade e o modelo de urbanização propriamente dito (Neuhold, 2009; Tatagiba et al. [no prelo]; Blikstad, 2012). Sobretudo a partir de 1997, com as ocupações de imóveis ociosos na área central de São Paulo, essas organizações populares vêm consolidando um campo de atuação política e oferecendo um projeto alternativo aos modelos empresariais de "requalificação" do centro da cidade - que tendem a agravar a segregação socioespacial (Miagusko, 2008; Tatagiba, 2010; Tatagiba e Blikstad, 2011).

A rigor, a aplicação mais efetiva do Estatuto da Cidade depende de lutas nessa direção. Todavia, um balanço da literatura recente sobre o Estatuto (Maricato, 2010, 2011; Fernandes e Alfonsin, 2009; Fernandes, 2007, 2010) nos revela um consenso entre os estudiosos no Brasil: a referida lei ainda não saiu do papel, ao menos não da forma como muitos desejam. Para isso, ainda será necessário um volume significativo de articulação e mobilização popular, cujo desafio consiste em alterar de modo concreto a correlação de forças vigente na sociedade brasileira - há muito dependente e subordinada aos interesses dos setores patrimonialistas (Maricato, 2000, 2010; Ribeiro, 2003; Quinto Júnior, 2003). Isso não significa diminuir a impor- 
tância dos avanços obtidos no campo jurídico-legal com a aprovação do Estatuto da Cidade; pelo contrário, significa reconhecer que, com a aprovação dessa lei, foi dado um passo fundamental no combate ao excludente modelo de urbanização brasileiro, e que a mobilização social não se encerra no momento da aprovação de textos e normas legais. Ou seja, uma legislação avançada é condição necessária, mas não suficiente para a realização de uma reforma profunda nos alicerces estruturais de qualquer sociedade. Na qualidade de um direito social, portanto, o direito à cidade exige, nos termos de Danilo Zolo (2005), uma "permanente luta” por sua efetivação.

Levando-se em conta o debate atual acerca do direito à cidade, consideramos que nossa contribuição principal 160 neste artigo se deu no sentido de oferecer um exame da dimensão jurídica desse conceito, uma perspectiva de análise pouco explorada pelos estudiosos do tema. Mais do que isso, à medida que procuramos situar o direito à cidade no debate teórico sobre os direitos e a cidadania a partir da contribuição de alguns autores clássicos, foi possível formalizar nosso argumento e conferir maior densidade analítica à proposta. Ao interpretarmos o direito à cidade enquanto um direito social, percebemos como sua aplicação efetiva é uma questão delicada do ponto de vista político. Aceitar essa definição implica, por consequência, refutar qualquer argumentação pautada em critérios puramente técnicos e institucionais para avaliar as dificuldades de efetivação da lei em questão, de um lado, bem como um raciocínio simplista e precipitado, cuja tendência seria concluir que o direito e a lei não representam nenhum papel relevante na dinâmica das relações e das lutas sociais, de outro. 
É curioso constatar que na literatura mais recente acerca do direito à cidade haja tão poucos esforços em relacionar esse conceito a uma discussão mais próxima da dimensão jurídica e institucional. Talvez isso seja uma herança do próprio Lefebvre, visto que sua proposta original não se preocupava em abarcar esse aspecto. Contudo, do nosso ponto de vista, essa lacuna deveria ser, na verdade, um incentivo para a realização de uma empreitada teórica capaz de contemplar a dimensão jurídica desse direito, especialmente quando consideramos que, no mundo contemporâneo, há um ataque cada vez mais implacável aos direitos sociais existentes. Por essa razão, e até mesmo em função do precedente aberto pela aprovação do Estatuto da Cidade no Brasil, a dimensão legal deveria ser uma preocupação mais presente para estudiosos e pesquisadores voltados ao problema.

Com relação às possibilidades de aplicação efetiva do Estatuto da Cidade no Brasil, deve-se ressaltar que o caminho será longo e repleto de obstáculos. Uma das heranças mais significativas da formação colonial brasileira consiste em uma mentalidade patrimonialista fortemente arraigada no tecido social, o que contribui de maneira decisiva para reforçar a concepção do direito de propriedade privada como algo sagrado e inviolável, inclusive por aqueles que não a detém. A transformação de nosso excludente e perverso modelo de desenvolvimento urbano não passa apenas pela aprovação de boas leis, mas também por uma profunda transformação sociocultural e política, o que só pode ser construído a longo prazo, com a intensificação gradual das lutas sociais. Chega a ser irônico, mas, se consideramos que uma sociedade liberal se define pelo maior ou menor grau em que a ação do Estado limita o direito à propriedade individual em benefício dos interesses coletivos, na prática, talvez o Brasil seja um país muito mais liberal do que algumas nações pertencentes ao mundo desenvolvido do capitalismo. 


\section{Thiago Aparecido Trindade}

é doutorando em ciências sociais do IFCH/Unicamp.

\section{Referências bibliográficas}

BARROS, A. M. F. B. et al. 2010. "O estatuto da cidade comentado (Lei n. 10.257 de 10 de julho de 2001)". In: CARVALHO, C. S.; ROSSBACH, A. (orgs.). O estatuto da cidade: comentado. São Paulo: Ministério das Cidades/ Aliança das Cidades, 2010, pp.91-118.

BASSUL, J. R. 2010. "Estatuto da cidade: a construção de uma lei”. In: CARVALHO, C. S.; ROSSBACH, A. (orgs.). O estatuto da cidade: comentado. São Paulo: Ministério das Cidades/ Aliança das Cidades, 2010, pp.71-90.

BLIKSTAD, K. 2012. O agir coletivo nas interfaces da sociedade civil e do sistema político: o caso da atuação do movimento de moradia de São Paulo sobre a política pública de habitação. Campinas, 194p. Dissertação de mestrado. Instituto de Filosofia e Ciências Humanas da Universidade Estadual de Campinas.

BOBBIO, N. 1992. A era dos direitos. Rio de Janeiro: Campus.

BRASIL. Lei n. 10.257, de 10 julho de 2001, que regulamenta os arts. 182 e 183 da Constituição Federal, estabelece diretrizes gerais da política 162 urbana e dá outras providências. Diário Oficial da República Federativa do Brasil, ano 138, n.133, p. 1-2, 11 jul. 2001. Seção 1.

CAMPOS FILHO, C. M. 1989. Cidades brasileiras: seu controle ou o caos - o que os cidadãos devem fazer para humanização das cidades no Brasil. São Paulo: Nobel.

CARDOSO, A. L. 2003. "A cidade e seu estatuto: uma avaliação urbanística do estatuto da cidade”. In: RIBEIRO, L. C. Q.; CARDOSO, A. L. (orgs.). Reforma urbana e gestão democrática. Rio de Janeiro: Revan.

ESTADÃO. 2010. "São Paulo tem 290 mil imóveis sem moradores", 7 de dezembro. Disponível em http://www.estadao.com.br/noticias/ impresso,sp-tem-290-mil-imoveis-sem-moradores,650404,0.htm. Acesso em 29/09/2012.

FERNANDES, E. 2007. "Constructing the 'right to the city' in Brazil". Social Ẽ Legal Studies, v.16, n.2, pp.201-19.

2010. "O estatuto da cidade e a ordem jurídico-urbanística". In: CARVALHO, C. S.; ROSSBACH, A. (orgs.). O estatuto da cidade: comentado. São Paulo: Ministério das Cidades/ Aliança das Cidades, 2010, pp. 55-70.

FERNANDES, E; ALFONSIN, B. 2009. "Estatuto da cidade: razão de descrença ou de otimismo? Adicionando complexidades à reflexão sobre a 
efetividade da lei”. Disponível em http://bdjur.stj.jus.br/dspace/handle/2011/29672. Acesso em 29/09/2012.

GRAZIA, G. 2003. "Reforma urbana e estatuto da cidade". In: RIBEIRO, L. C. de Q.; CARDOSO, A. L. (orgs.). Reforma urbana e gestão democrática. Rio de Janeiro: Revan.

HARVEY, D. 2008. "The right to the city". New Left Review, v.53, pp.23-40.

HERRERA, C. M. 2003. "Estado, constitución y derechos sociales". Revista Derecho Del Estado, n.15, pp.75-92.

KOWARICK, L. 1980. A espoliação urbana. Rio de Janeiro: Paz e Terra. 2009. Viver em risco: sobre a vulnerabilidade socioeconômica e civil. São Paulo: Editora 34.

LEFEBVRE, H. [1968] 2008. O direito à cidade. São Paulo: Centauro.

MARCUSE, P. 2010. "Os direitos nas cidades e o direito à cidade". In: SUGRANYES, A.; MATHIVET, C. (orgs.). Cidades para todos: propostas e experiências pela direito à cidade. Santiago: Habitat International Coalition.

MARICATO, E. 1994. "Reforma urbana: limites e possibilidades - uma trajetória incompleta”. In: RIBEIRO, L. C. Q.; SANTOS JR., O. A. (orgs.). Globalização, fragmentação e reforma urbana: o futuro das cidades brasileiras na crise. Rio de Janeiro: Civilização Brasileira. 1996. Metrópole na periferia do capitalismo: ilegalidade, desigualdade e violência. São Paulo: Hucitec.

2000. "As ideias fora do lugar e o lugar fora das ideias". In: ARANTES, O. et al. (orgs.). A cidade do pensamento único: desmanchando consensos. Petrópolis: Vozes.

2010. "O estatuto da cidade periférica”. In: CARVALHO, C. S.; ROSSBACH, A. (orgs.). O estatuto da cidade: comentado. São Paulo: Ministério das Cidades/ Aliança das Cidades, 2010, pp.5-22.

. 2011. "Metrópoles desgovernadas". Estudos Avançados, v.25, n.71, pp.7-22.

MARSHALL, T. H. [1949] 1967. Cidadania, classe social e status. Rio de Janeiro: Zahar.

MIAGUSKO, E. 2008. Movimentos de moradia e sem-teto em São Paulo: experiências no contexto do desmanche. São Paulo, 241p. Tese de doutorado. Faculdade de Filosofia Letras e Ciências Humanas da Universidade de São Paulo.

MITCHELL, D. 2003. The right to the city: social justice and the fight for public space. New York: Guilford.

NEUHOLD, R. R. 2009. Os movimentos de moradia e sem-teto e as ocupações de móveis ociosos: a luta por políticas públicas habitacionais na área cen- 
tral da cidade de São Paulo. São Paulo, 259p. Dissertação de mestrado. Faculdade de Filosofia Letras e Ciências Humanas da Universidade de São Paulo.

PLYUSHTEVA, A. 2009. "The right to the city and the struggles over public citizenship: exploring the links". Disponivel em http://www.urbanreinventors.net/3/plyushteva/plyushteva-urbanreinventors.pdf. Acesso em 29/12/2012.

PURCELL, M. 2003. "Citizenship and the right to the global city: reimagining the capitalist world order". International Journal of Urban and Regional Research, v.27, n.3, pp.1564-90.

QUINTO JÚNIOR, L. P. 2003. "Nova legislação urbana e os velhos fantasmas”. Estudos Avançados, v.17, n.47, pp.187-96.

RIBEIRO, L. C. Q. 2003. "O estatuto da cidade e a questão urbana brasileira”. In: RIBEIRO, L. C. Q.; CARDOSO, A. L. (orgs.). Reforma urbana e gestão democrática. Rio de Janeiro: Revan.

RODRIGUES, A. M. 1988. Moradia nas cidades brasileiras. São Paulo: Contexto. 2006. "Luchas por el derecho a la ciudad". Scripta Nova, v.X, n.18, pp.10-31.

SAES, D. A. M. 2003. "Cidadania e capitalismo: uma crítica à concepção liberal de cidadania”. Crítica Marxista, n.16, pp.9-38.

164 SANTOS, M. 1990. Metrópole corporativa fragmentada: o caso de São Paulo. São Paulo: Nobel.

SILVA, C. A. 2002. "Os fóruns temáticos da sociedade civil: um estudo sobre o Fórum Nacional de Reforma Urbana”. In: DAGNINO, E (org.). Sociedade civil e espaços públicos no Brasil. São Paulo: Paz e Terra.

SILVA, J. P. 2010. "Nota crítica sobre cidadania no Brasil”. Ideias, v.1, n.1, pp.95-119.

SOUKI, L. G. 2006. "A atualidade de T. H. Marshall no estudo da cidadania no Brasil”. Civitas, v.6, n.1, pp.39-58.

SOUZA, M. 2004. Mudar a cidade: uma introdução crítica ao planejamento e à gestão urbanos. Rio de Janeiro: Bertrand Brasil.

2010. "Which right to which city? In defense of political-strategic clarity". Interface, v.2, pp.315-33.

TATAGIBA, L. 2010. "Relação entre movimentos sociais e instituições políticas na cidade de São Paulo. O caso do movimento de moradia”. In: KOWARICK, L.; MARQUES, E. (orgs.) São Paulo: olhares cruzados. Sociedade, Política e Cultura: Flacso/ Quito.

; BLIKSTAD, K. 2011. “'Como se fosse uma eleição para vereador’: dinâmicas participativas e disputas partidárias na cidade de São Paulo". Lua Nova, n.84, pp.175-217. 
et al. [no prelo]. "Ocupar, reivindicar, participar: sobre o repertório de ação do movimento de moradia de São Paulo".

VILLAÇA, F. 1998. Espaço intraurbano no Brasil. São Paulo: Studio Nobel.

ZOLO, D. 2005. "Libertad, propiedad e igualdad en la teoría de los derechos fundamentales: a propósito de un ensayo de Luigi Ferrajoli”. In: FERRAJOLI, L. (org.) Los fundamentos de los derechos fundamentales. Madrid: Trotta. 


\section{DIREITOS E CIDADANIA: REFLEXÕES SOBRE $O$ DIREITO À CIDADE}

\section{THIAGO APARECIDO TRINDADE}

Resumo: Este artigo procura se inserir no debate contemporâneo sobre o direito à cidade a partir de duas perspectivas analíticas: a primeira, jurídico-institucional, toma como base o Estatuto da Cidade, legislação brasileira aprovada em 2001; a segunda, teórica, envolve o debate clássico acerca dos direitos e cidadania, especialmente as contribuições de Thomas Marshall e Norberto Bobbio a este. Essas perspectivas, que são fundamentais para o aperfeiçoamento do debate teórico sobre o direito à cidade, pouco se fazem presentes na discussão atual sobre o tema.

Palavras-chave: Direito à Cidade; Espaço Urbano; Função Social da Propriedade; Estatuto da Cidade; Direitos Sociais.

RIGHTS AND CITIZENSHIP: REFLECTIONS ON THE RIGHT TO THE CITY

Abstract: This article introduces itself into the contemporary debate on the right to the city from two analytical perspectives: first, legal- 
institutional, is based on the City Statute, a Brazilian legislation approved in 2001; the second, theoretical, involves the classic debate about rights and citizenship, especially the contributions of Thomas Marshall and Norberto Bobbio to it. These perspectives, which are fundamental for the improvement of the theoretical debate on the right to the city, are scarcely present in the current discussion about that topic.

Keywords: Right to the City; Urban Space; Social Function of Property; City Statute; Social Rights.

Recebido: 17/10/2011 Aprovado: 02/07/2012 